Research Article

\title{
Vehicle-Bridge Coupling Vibration Analysis for Simply Supported Girders of High-Speed Railway Bridges Based on the Cross-Sectional Decentralized Centre of Mass and Shear
}

\author{
Chen Daihai $\mathbb{D},{ }^{1}$ Zhou Shuai $\mathbb{D}^{1},{ }^{1}$ Xu Shizhan $\mathbb{D}^{1},{ }^{1}$ Li Zheng $\mathbb{D}^{1},{ }^{1}$ and Fang Yilin $\mathbb{D}^{2}$ \\ ${ }^{1}$ School of Civil Engineering, Zhengzhou University, Zhengzhou 450001, China \\ ${ }^{2}$ Henan Expressway Development Corporation Ltd., Zhengzhou, Henan 450052, China
}

Correspondence should be addressed to Xu Shizhan; zhoushuai1115@163.com

Received 29 July 2021; Accepted 11 October 2021; Published 8 November 2021

Academic Editor: Nicolo Zampieri

Copyright (c) 2021 Chen Daihai et al. This is an open access article distributed under the Creative Commons Attribution License, which permits unrestricted use, distribution, and reproduction in any medium, provided the original work is properly cited.

Taking the simply supported box girder bridge of high-speed railway as an example, the effect of cross-sectional decentralized centre of mass and shear on the spatial beam element stiffness matrix was theoretically derived. Based on the vehicle-bridge coupling vibration analysis method of the railway bridge, an analysis program of vehicle-bridge coupling vibration for the highspeed railway was compiled, and its reliability was verified through an example analysis. On this basis, considering the crosssectional decentralized centre of mass and shear, the influence factors of vehicle-bridge coupling vibration response were studied, which included the offset distance of the beam section's mass and shear centre, offset distance of track centreline, vehicle weight, and vehicle speed. The results show that the additional items of the spatial beam element stiffness matrix are generated by the torsion effect when the cross-sectional decentralized centre of mass and shear is considered, and it will affect the lateral and vertical stiffness of the element. The cross-sectional decentralized centre of mass and shear has a significant effect on the lateral dynamic response of the bridge's mid-span, but the influence on the vertical response of the bridge and the dynamic response of the car body is small. The main influence factors of the lateral dynamic response of the bridge are the vertical offset distance of the beam section's centre of mass and shear, the lateral offset distance of the track centreline, and the vehicle weight.

\section{Introduction}

In the numerical analysis of coupled bridge-vehicle-bridge vibrations, spatial beam units are often used in discrete bridge structures. To improve the efficiency and accuracy of calculating the structural deformation and internal forces of beam units, many scholars have used Timoshenko beam theory as the basis for deriving the stiffness matrix of spatial beam units considering shear effects by specifying a reasonable form function for the unit deformation and combining it with the principle of minimum potential energy or virtual work [1]. However, these papers all implicitly assume that the centre of mass of the unit section coincides with the centre of shear. This is undoubtedly accurate for symmetrical regular section beams, but in engineering practice, many structural members have irregular cross sections, where the mass and shear centres are often not in the same position, known as "section mass-shear heterocentricity," which will produce certain deviations in the beam unit stiffness matrix and thus affect the stiffness distribution of the whole bridge structure. At the same time, high-speed railway bridges have strict design parameters and high requirements for safety and comfort in train operation, while they often use irregular (asymmetrical about the cross axis of the section) box girder sections. Also, it is necessary to explore the issue in depth as to how much the mass-shear heterocentre affects the coupled vibration response of this type of bridge.

At present, a lot of work has been carried out by many scholars about coupled vehicle-bridge vibration of highspeed railways [2-5]. Guo et al. [6] established a finite element model of high-speed railway bridges and used the bridge-rail deformation mapping model to calculate the rail 
deformation caused by bridge deformation and as an excitation of the vehicle-rail-bridge system to study the effect of bridge deformation on the dynamic response of trains. Liu and Guo [7] by calculating the inertia loads, damping loads, elastic loads, and the total virtual work done by fluctuating electromagnetic loads, the global mass matrix, damping matrix, stiffness matrix, and coefficient matrix of fluctuating electromagnetic forces in the maglev vehicle were reasonably combined to study the spatial vibration characteristics of two middle-low-speed vehicles travelling along a long-span bridge with double lines. Xu et al. [8] used the principle of dynamic equivalence to equate the compression deformation of the PC beam and the effect of the finger belt on the train to the load spectrum of the train axle and finally established a train-track interaction model to simulate the vertical vibration of the train by adding the compression deformation of the track beam, respectively. Based on the rigid-flexible coupling method, Bao et al. [9] investigated the geometric and mechanical coupling relationship between the vehicle and bridge by considering the compression deformation and contact model of walking tire and guiding tire, established a vehicle-curved bridge coupled vibration system, and explored the effects of key system parameters such as the superelevation, vehicle speed, and bridge curve radius on the dynamic response of the vehicle and curved bridge. Shi et al. [10] used the idea of dynamic flexibility to establish a frequency-domain model of high-speed railway vehicle-track-bridge vertical coupling dynamics and solved the dynamic response of the track system and bridge structure under unit simple harmonic excitation and wheelrail geometric roughness excitation, respectively. Based on multibody dynamics and finite element methods, Gao et al. [11] have developed a coupled vehicle-bridge model by SIMPACK and ANSYS. A 3D model of the bridge was built in ANSYS, and a vehicle model with 35 degrees of freedom was built in SIMPACK. The effects of vehicle speed, bridge pier height, track unevenness, and vehicle loads on ride comfort were investigated. Xie et al. [12] established a bridge model of the steel spring floating slab track and the CRTSIII ballastless track considering the shock-absorbing steel spring, the limit barricade, and the contact characteristics of track structure layers. By studying the influence of the speed of train on the bridge, the damage of fasteners and the parameters of track structure on the train-track-bridge system, displacement of rail, vertical vibration acceleration, and wheel-rail force response performance are analyzed. Based on the multibody dynamic finite element method, Wang and $\mathrm{Li}$ [13] analyzed the vertical and lateral vibrations of the box girder, U-girder, and track structures when the train passes through the bridge. For the box girder bridge, the influences of parameters of fastener, elastic support under the track plate, and support were analyzed and the reasonable range of each parameter was given.

Due to the complexity of the coupled vibration mechanism of railway bridges and trains, it is generally difficult for general-purpose finite element software to accurately consider the complex wheel-rail interaction relationship. In the finite element analysis of bridge structures, none of the literature [2-13] has considered the effect of mass-shear heterocentricity of the cross section. There are even fewer studies on the coupled vibration analysis of the bridge considering the mass-shear heterocentre. Therefore, in this paper, a specific expression for the stiffness matrix of the spatial beam unit considering the mass-shear heterocentricity of the section is derived based on the finite element analysis theory. Based on the railway bridge coupled vibration analysis method, the influence of the main girder section mass-shear offset distance, track centre offset distance, vehicle weight, vehicle speed, and other factors on the coupled vibration response of the high-speed railway simply supported girder bridge is investigated in detail, taking into account the section mass-shear heterocentricity. The conclusions obtained can provide a reference for the numerical analysis of the coupled vibration of railway bridges and provide a reliable reference basis for the actual engineering construction to avoid some blindness and inefficiency in the actual construction.

\section{Derivation of Expressions for the Stiffness Matrix of a Spatial Beam Unit considering Mass-Shear Heterocentricity of the Section}

For a spatial beam cell [14], the centre-of-mass coordinate system is chosen as shown in Figure 1, with the origin of the local coordinate system taken at the centre of mass on the left face of the cell, $c$ being the centre of mass, the $x$-axis taken at the form centre axis of the cell, the $y$-axis and $z$-axis being the two form centre principal axes of inertia, and the generalised displacements and generalised forces at the $i$ and $j$ ends denoted by $u_{i}$ and $R_{i}(i=1,2, \ldots, 12)$.

The unit stiffness equation is then of the following form:

$$
[K]\{u\}=\{R\} .
$$

The generalised force vector $\{R\}$ is a 12-dimensional column vector.

$$
\{R\}=\left\{R_{1}, R_{2}, \ldots, R_{12}\right\}^{T} .
$$

The generalised displacement vector $\{u\}$ is a 12-dimensional column vector.

$$
\{u\}=\left\{u_{1}, u_{2}, \ldots, u_{12}\right\}^{T} .
$$

The unit stiffness matrix $[K]$ is a symmetric square matrix of order $12 \times 12$, which will not be elaborated since the derivation process is more detailed in the literature [15]. In the case of concentric mass and shear of the section, the beam unit stiffness matrix considering the shear effect is given by the following equation: 


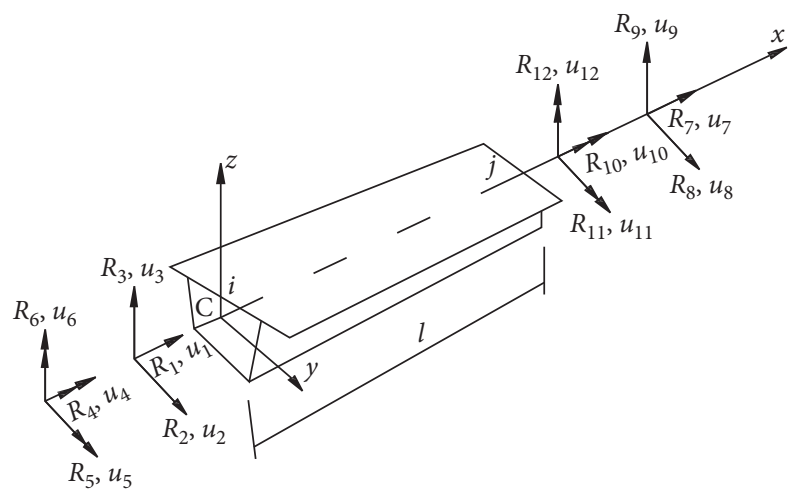

Figure 1: Schematic diagram of a spatial beam unit.

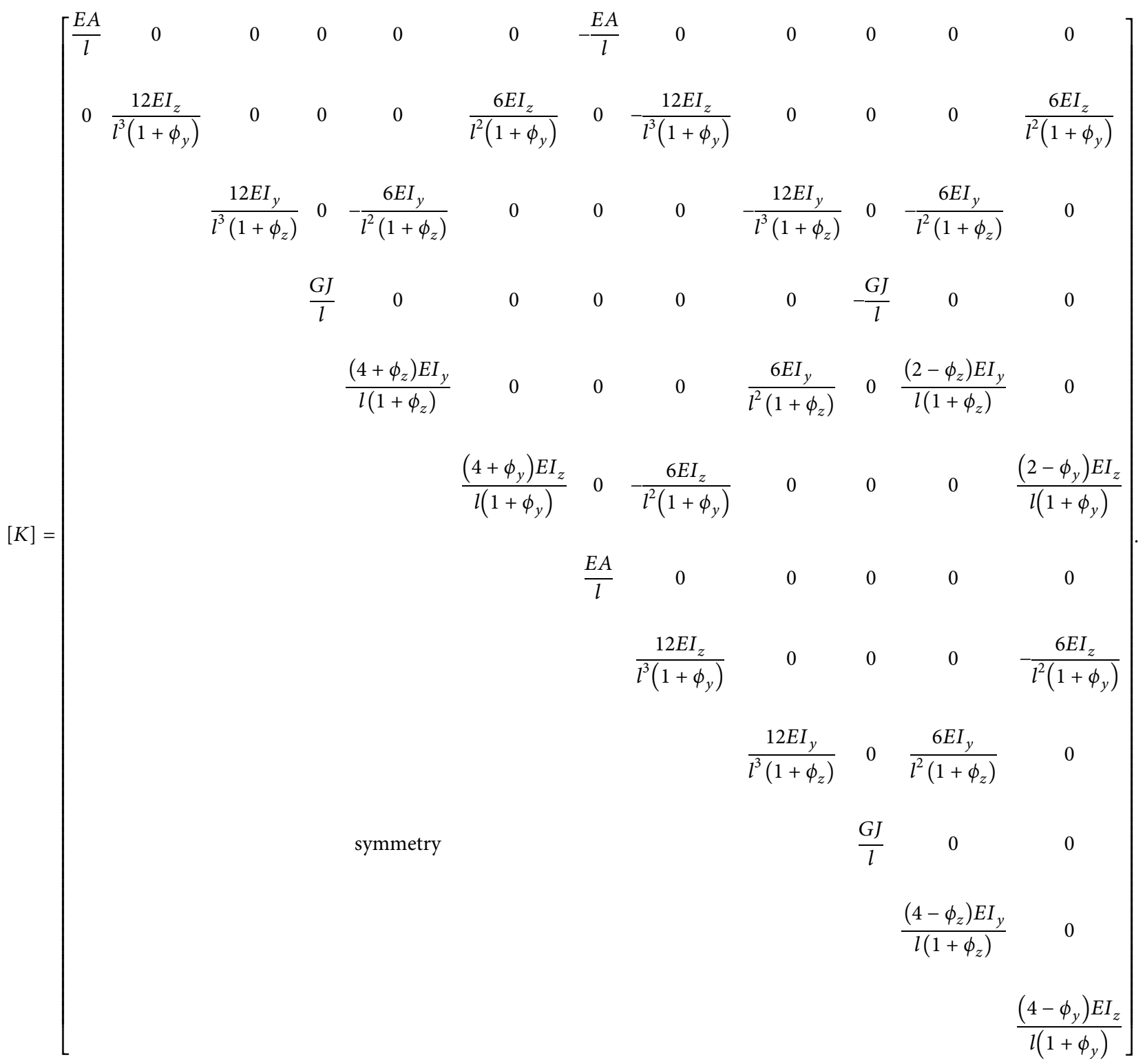




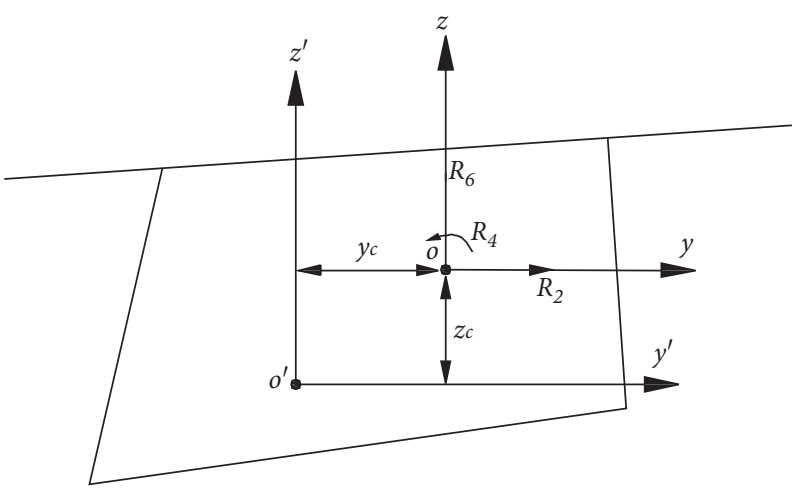

FIgURE 2: Irregular beam unit section.

$E$ is the modulus of elasticity; $A$ is the cross-sectional area of the unit; $l$ is the length of the unit; $G$ is the shear modulus; $J$ is the torsional moment of inertia; $I_{y}$ is the moment of inertia around the $y$-axis; $I_{z}$ is the moment of inertia around the $z$-axis; $\phi_{y}=12 k_{y} E I_{z} / G A l^{2}$ and $\phi_{z}=12 k_{z} E I_{y} / G A l^{2}$ are the coefficients of shear influence in the $y$ - and $z$-axis directions, respectively; and $k_{y}$ and $k_{z}$ are the coefficients of shear deformation along the $y$ - and $z$-axis directions, respectively.

In deriving the stiffness matrix of a spatial beam element in a local coordinate system, the generalised displacements and forces at the nodes correspond to the centre of mass of the section, while the generalised displacements and forces reflecting torsion correspond to the shear centre of the section [16]. According to the definition of the shear centre, the moments of the section are only guaranteed to be in equilibrium if the forces acting on the structural members pass through the shear centre of the section. If the load is assumed to act at the centre of mass of the section, additional moments will be generated as the centre of mass of the section does not coincide with the centre of shear. After noting the difference between the centre of mass and the centre of shear of the section, the derivation of the stiffness matrix of the beam unit considering the mass-shear heterocentre of the section requires the inclusion of the torsional effects.

Define the section centre coordinate system as $o x y z$, the shear centre coordinate system as $o^{\prime} x^{\prime} y^{\prime} z^{\prime}$, and the rod end force over the centre of the section as $R_{i}$. The coordinates of the shear centre $o^{\prime}$ point in the $y o z$ plane are $\left(y_{c}, z_{c}\right)$, as shown in Figure 2.

In the centre-of-mass coordinate system, when a displacement $u_{2}$ occurs at the end of the $\operatorname{rod} i$ along the $y$-axis, it causes not only a reaction force $R_{2}$ along the $y$-direction and a bending moment $R_{6}$ around the $z$-axis but also an additional force dipole moment $R_{4}$ at the same time, whose value is equal to the product of the reaction force $R_{2}$ in that direction and the difference $z_{c}$ between the two centres of the mass and shear in the $z$-direction, i.e., $R_{4}=-R_{2} \cdot z_{c}$, as shown in Figure 2. Similarly, the reaction forces $R_{8}$ and $R_{12}$ and the moment $R_{10}=R_{8} \cdot z_{c}$ at the $j$ end of the cell are derived to obtain the reaction forces at both of the cell due to displacement $u_{2}$. The specific values of the reaction forces due to $u_{2}=1$ are given in Table 1 .

By analogy, the values of the reaction force at the end of the unit when the unit produces unit displacements $u_{3}, u_{5}$, $u_{6}, u_{8}, u_{9}, u_{11}$, and $u_{12}$ can be derived are as shown in Table 2 .

When the unit section is rotated by an angle of $\theta$ around the centre of mass axis, this corresponds to the section first being rotated by an angle of $\theta$ around the shear axis (displacement shown by the double dotted line), then displaced by $z_{c} \cdot \theta$ in the $y$-direction, and later displaced by $-y_{c} \cdot \theta$ in the $z$-direction (displacement shown by the dashed line), as shown in Figure 3.

In the case of small elastic deformations, the reaction force resulting from the rotation of the unit around the centre-of-mass axis can be obtained by superimposing the reaction force resulting from these three partial displacements. Since the magnitude of the force dipole moment is independent of the displacement of the torsional centre, the reaction force of the unit rod end against the torsion centre is equal to the reaction force of the rod end against the form centre. Tables 1 and 2 will be obtained from the unit along the $y$-axis for displacement $z_{c} \cdot \theta$ and along the $z$-axis for the displacement $-y_{c} \cdot \theta$; by the resulting reaction force and the unit around the torsion centre of the reaction force superimposed, you can get the unit around the axis in the form of the reaction force generated by the rotation, as shown in Table 3.

Combining the data in Tables $1-3$, the stiffness matrix of the spatial beam unit in the form-centred coordinate system can be expressed as follows when considering the shear effect at the mass-shear heterocentre of the section: 
TABLE 1: Values of unit end reaction forces induced at $u=1$.

\begin{tabular}{ccccccc}
\hline & $R_{2}$ & $R_{4}$ & $R_{6}$ & $R_{8}$ & $R_{10}$ & $R_{12}$ \\
\hline$u_{2}=1$ & $12 E I_{z} / l^{3}\left(1+\phi_{y}\right)$ & $-\left(12 E I_{z} z_{c} / l^{3}\left(1+\phi_{y}\right)\right)$ & $6 E I_{z} / l^{2}\left(1+\phi_{y}\right)$ & $-\left(12 E I_{z} / l^{3}\left(1+\phi_{y}\right)\right)$ & $12 E I_{z} z_{c} / l^{3}\left(1+\phi_{y}\right)$ & $6 E I_{z} / l^{2}\left(1+\phi_{y}\right)$ \\
\hline
\end{tabular}

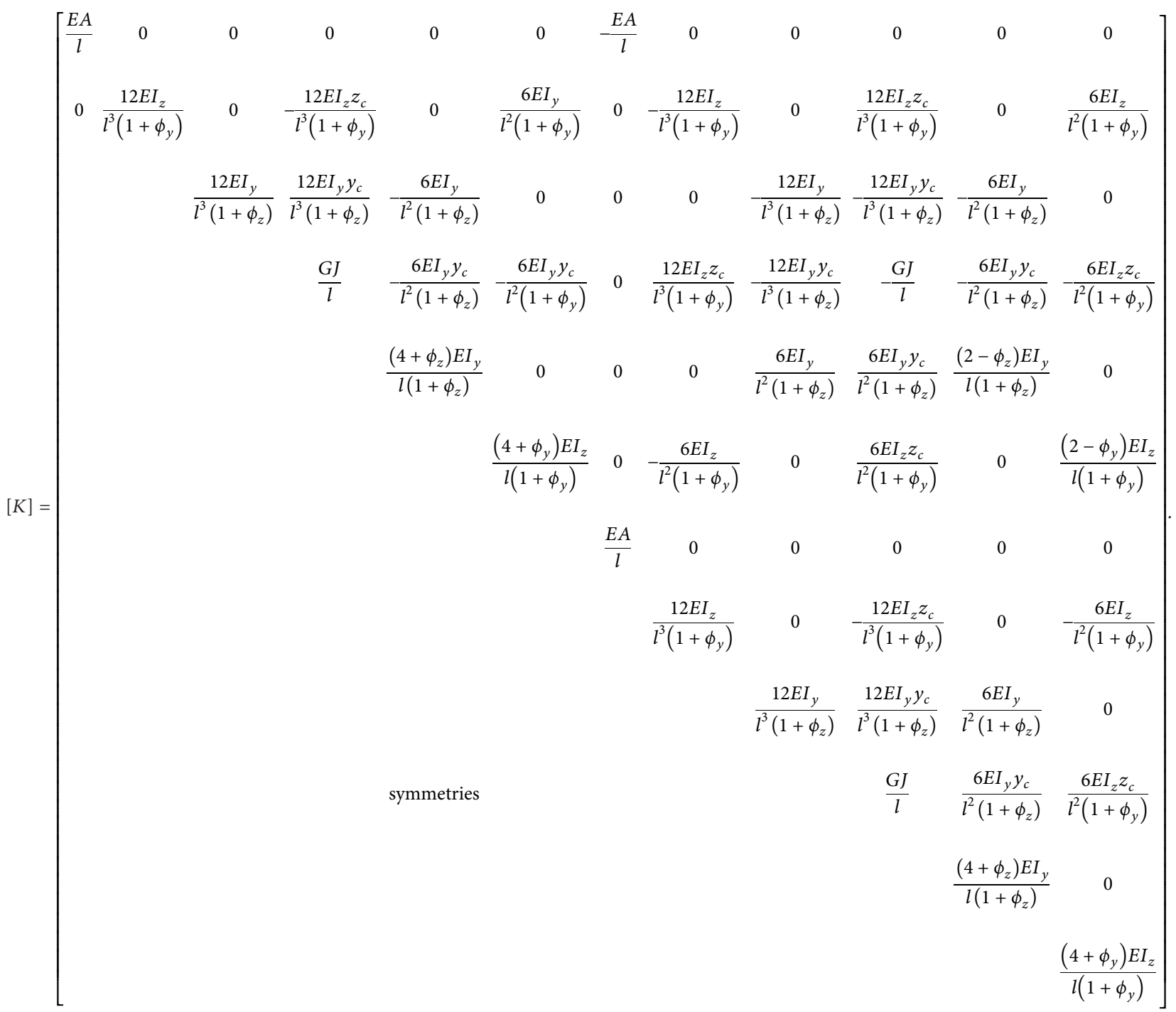

In equation (5), the bolded red part is the additional term in the stiffness matrix of the spatial beam unit when the mass-shear eccentricity of the section is considered. It can be seen from the above equation that when a unit section is mass-shear heterocentric, the torsional effect affects the lateral and vertical degrees of freedom of the unit nodes, with the lateral and vertical stiffnesses being proportional to the vertical and lateral distances of the mass-shear eccentricity, respectively.

\section{Coupled Vibration Analysis Methods for High-Speed Railway Axles}

For the coupled train-track-bridge system, the whole system is divided into the train subsystem and the track-bridge subsystem [17], and its equations of motion are established separately and the two subsystems are linked through the wheel-rail interaction relationship. In the time domain, the equations of motion of the axle are solved and the coupled vibration response of the axle is obtained.

3.1. Rolling Stock Model and Its Equations of Motion. The train vehicle is simplified to a multirigid body system connected by spring damping elements. The four-axle vehicle model with two-system suspension consists of one body, two frames, and four wheel pairs with a total of seven rigid bodies, which are connected by longitudinal, transverse, and vertical spring damping elements, with antiroll springs and antisnaking dampers in the two-system 


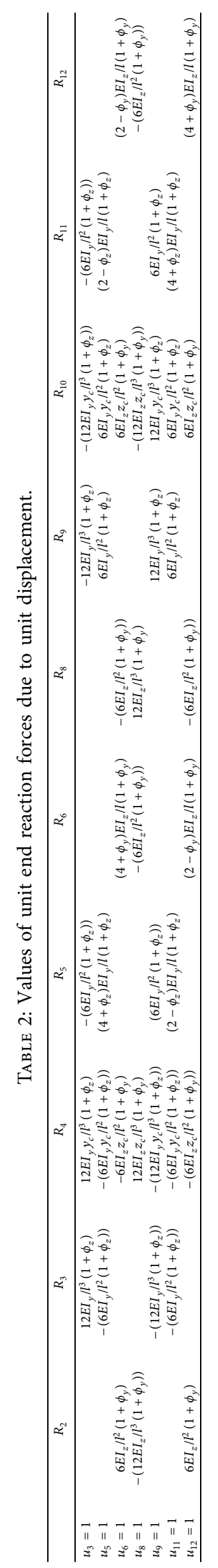




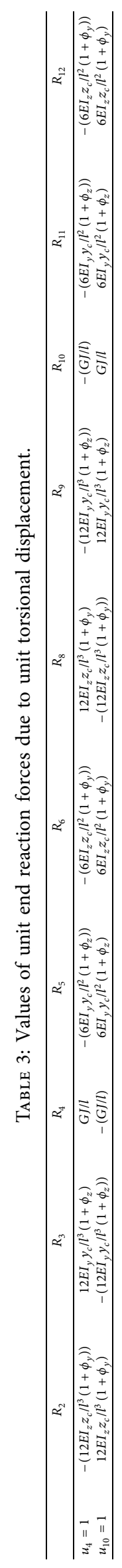




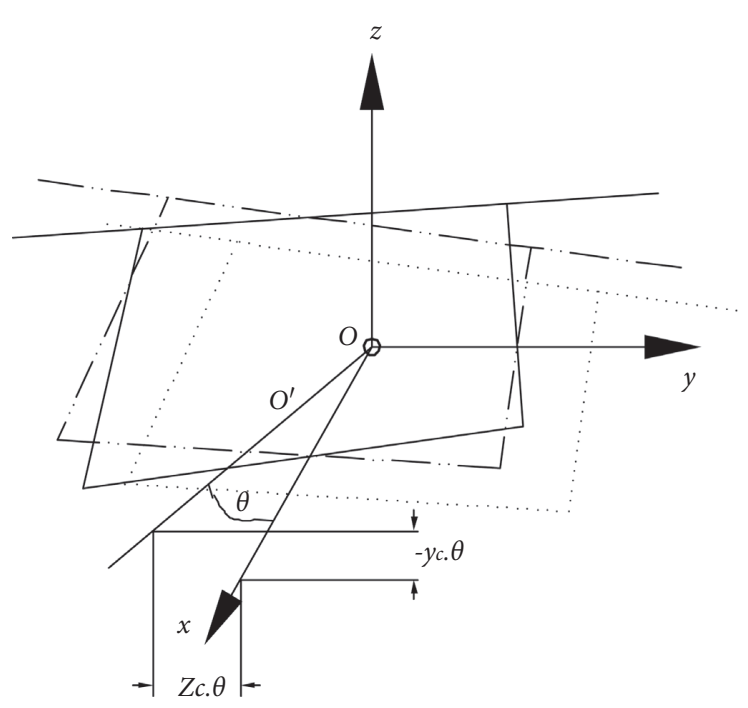

FIgURE 3: Beam unit torsional section deformation diagram.

suspension, with up to six degrees of freedom considered at each rigid body node [18], as shown in Figure 4.

Taking the stationary position of the vehicle under its own weight as the equilibrium state, according to D'Alembert's principle, the equilibrium equation of motion of the train vehicle is derived as follows:

$$
M_{v} \ddot{U}_{v}+C_{v} \dot{U}_{v}+K_{v} U_{v}=F_{v}
$$

$\ddot{U}_{v}, \dot{U}_{v}$, and $U_{v}$ are the vehicle rigid body node acceleration, velocity, and displacement column vectors, respectively; $M_{v}, C_{v}$, and $K_{v}$ are the overall mass, damping, and stiffness matrices of the vehicle, respectively; and $F_{v}$ is the external load matrix to which the vehicle is subjected, mainly the force acting between the wheels and rails, excluding the vehicle's self-weight.

\subsection{Bridge-Track Finite Element Model and Its Equations of} Motion. The bridge-track structure is modelled using the conventional finite element method, and the main beam is discretized with a spatial beam unit that can take into account the mass-shear heterocentricity; the equations of motion of the bridge-track structure are obtained in the following equation, using the initial state as the equilibrium position regardless of the self-weight of the structure:

$$
M_{b} \ddot{U}_{b}+C_{b} \dot{U}_{b}+K_{b} U_{b}=F_{b} .
$$

$\ddot{U}_{b}, \dot{U}_{b}$, and $U_{b}$ are the structural nodal acceleration, velocity, and displacement column matrices of the structure nodes, respectively; $M_{b}, C_{b}$, and $K_{b}$ are the overall mass, damping, and stiffness matrices of the structure, respectively; and $F_{b}$ is the external load matrix on the structure, mainly including wheel-rail interaction forces and vehicle weight.

3.3. Wheel-Track Interaction Relationship. The wheel-rail interaction relationship is reflected in the coordination of displacements and the balance of forces at the wheel-rail

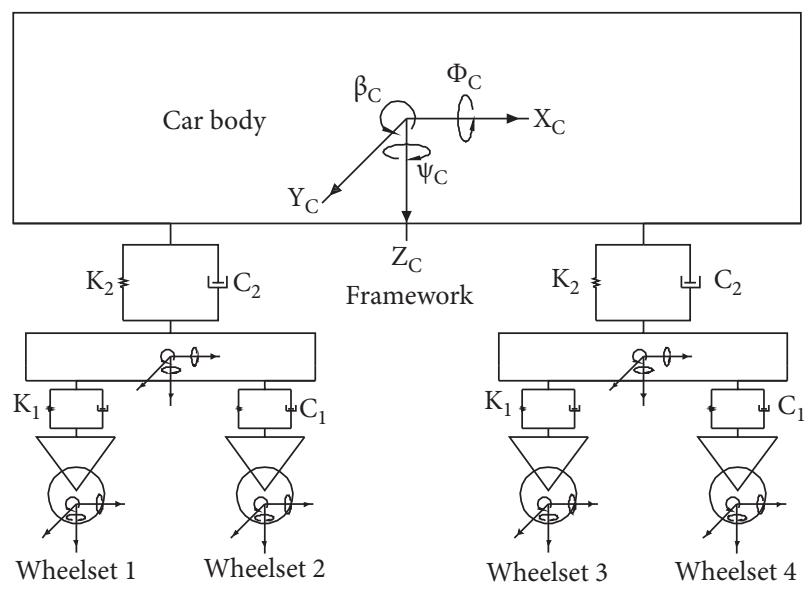

Figure 4: Side view of the rolling stock model.

contact points. In the new dynamic wheel-rail contact geometry relationship, the spatial coordinates of the wheel-rail contact point on the wheel tread surface $\left(x_{c}, y_{c}, z_{c}\right)$ are solved using the trace method and combined with the coordinate values of the contact point at the corresponding position on the rail head $\left(y_{g}, z_{g}\right)$ to obtain the wheel-rail vertical compression $\delta z$ as the following equation:

$$
\delta z=z_{c}-z_{g}
$$

Wheel-rail vertical compression is a function of wheel pair displacement, rail displacement, and track unevenness, showing the coordination of displacements in wheel-rail contact.

From the geometric relationship between the vertical compression of the wheel track and its normal compression, the normal elastic compression of the wheel track is obtained and then the normal force of the wheel track is found according to the Hertz nonlinear contact theory. At the same time, the longitudinal creep force, transverse creep force, and spin creep moment of the wheel track are calculated based on Kalker's linear creep theory and the Shen-Hedrick-Elkins theory is used for nonlinear correction. Finally, the resulting wheel-rail normal forces and creep slip forces (moments) are converted to the absolute coordinate system to obtain the external loads acting on the train subsystem and the bridge-track subsystem. It is worth noting that the wheel-rail interaction force is related to the displacement and velocity of the unknown wheel and track at the current time step when the vehicle is travelling on the bridge, so a new fast explicit integration method is required to predict the displacement and velocity to solve for the wheel-rail interaction force first. At the same time, as the vehicle is vibrating near its equilibrium position under its own weight, the only external loads acting on the vehicle are the wheel-rail interaction forces, while the external loads acting on the bridge need to have the weight of the vehicle added to them. The loads acting on the vehicle and the bridge at the wheel-rail contact point are a pair of forces of equal magnitude and opposite direction, which reflects the conditions for the balance of the interaction forces in the vehicle-bridge coupling relationship. 
3.4. Solution and Programming of Coupled Axle Vibration Balance Equations. The equations of motion of the coupled train-track-bridge system are solved jointly using the new fast explicit numerical integration method and the Newmark- $\beta$ method at each time step when the train is running on the bridge-track system, in the following steps:

(1) The new fast explicit integration method is used to predict the displacement and velocity of the coupled train-bridge system, and the parameters of the wheel-rail contact geometry relationship are calculated using the trace method in combination with the track unevenness value at the current moment.

(2) The wheel-rail interaction forces are calculated based on the wheel-rail contact geometry relationship. If the wheel-rail is not detached, the wheel-rail normal force is solved using Hertz nonlinear contact theory, the wheel-rail creep force is solved using Kalker linear theory, and the Shen-Hedrick-Elkins theory is used for nonlinear correction; if the wheel-rail is detached, the wheel-rail interaction force is zero.

(3) The load matrices of the train subsystem and the track-bridge subsystem are formed by considering the train weight and the wheel-rail interaction force.

(4) Equations (6) and (7) are solved using the Newmark$\beta$ method to obtain the dynamic response of the train subsystem and the track-bridge subsystem at the current time step, respectively.

According to the above coupled vibration analysis method of the vehicle and bridge, based on Microsoft Visual Studio 10.0 Platform, the dynamic analysis program of the coupled train-track-bridge system was prepared using Intel Visual Fortran language and the block diagram of the program is shown in Figure 5.

3.5. Axle Coupling Vibration Analysis Example Validation. A standard simply supported box girder for a high-speed railway is selected as an example. The girder is $32.6 \mathrm{~m}$ long, with a calculated span of $31.5 \mathrm{~m}$ and a net distance of $0.1 \mathrm{~m}$ between the ends of the two spans, and is arranged for 5 spans, without considering the piers. The simply supported boundary conditions are set according to the actual support arrangement form, and in order to fully reflect the vibration state of the train on the bridge, rails are laid $300 \mathrm{~m}$ before the bridge head and $200 \mathrm{~m}$ after the bridge tail. The fasteners are spaced $0.6 \mathrm{~m}$ apart, and spring damping units are used to simulate the connection between the fastener shims and the girder rails; the spring and damping coefficients are given in reference [18]. The main beam and rails are discretized using spatial beam units, and the main beam section is a single box, i.e., single chamber box beam as shown in Figure 6. The rails are selected from a standard section of $60 \mathrm{~kg} / \mathrm{m}$. The rail nodes are connected to the deck nodes by spring damping units, and the deck nodes are connected to the main girder nodes by stiffening arms. A finite element model of the bridge was built using general-purpose software ANSYS and then imported into vehicle-bridge coupling analysis software
SIMPACK to form the bridge analysis model [19]. In order to reduce the number of degrees of freedom in the model, only the left rail unit was created when the train was running on a single line, with a total of 5382 nodes and 5921 units for the whole bridge, as shown in Figure 7.

The train is an Ice3 high-speed passenger car, made up of eight vehicles, with the first and last cars being trailers and the middle six being moving cars. Each vehicle consists of one car body, two frames, and four wheel pairs, a total of seven rigid bodies, and each rigid body is connected by spring damping elements. The vehicle model parameters are shown in the literature [18], and the train formation and single-section vehicle models in SIMPACK are shown in Figure 8.

When the train passes the above bridge-track model at a uniform speed of $300 \mathrm{~km} / \mathrm{h}$, the dynamic response of the bridge and the train is calculated using the self-programmed program of this paper and SIMPACK. The results of SIMPACK and the self-programmed program were obtained for the same operating conditions, the same track length, the same bridge structural parameters, and the same analysis running time. Figures 9 and 10 present the comparative vertical and lateral displacement responses in the span of the bridge at span 3 . The comparative vertical response of the first car body is given in Figures 11 and 12.

From Figures 9 to 12, it can be seen that the trend of the dynamic response of the axle calculated by this paper and SIMPACK is basically the same, with slight differences in values. Considering the complexity of axle coupling vibration, different analysis programs have slightly different parameter settings and assumptions for the calculation process and the errors of the obtained calculation results are within the tolerance range, so it can be considered that the calculation results of this paper's self-programmed program and SIMPACK software are basically consistent, indicating that this paper's program can be used for the subsequent analysis of railway bridge axle coupling vibration.

\section{Analysis of the Effect of Cross-Sectional Mass- Shear Heterocentricity on the Coupled Vibration of High-Speed Railway Simply Supported Girders and Bridges}

Based on the above finite element model of the bridge, a low disturbance spectrum in Germany was considered to simulate the track upset value [15]. The procedure in this paper is used to calculate the dynamic response of the bridge when the train passes through the left lane of the bridge at a constant speed of $300 \mathrm{~km} / \mathrm{h}$. In this case, the horizontal and vertical dynamic response of the bridge is shown in the middle of span 3 and the horizontal and vertical dynamic response of the car body is shown in the head car. A comparison of the peak power response of the axle in both the section mass-shear heterocentric and concentric conditions is shown in Table 4. Figures 13 and 14 show the comparison of the span-to-span transverse displacement and acceleration timescales for span 3 with and without mass-shear heterocentric consideration, respectively. 


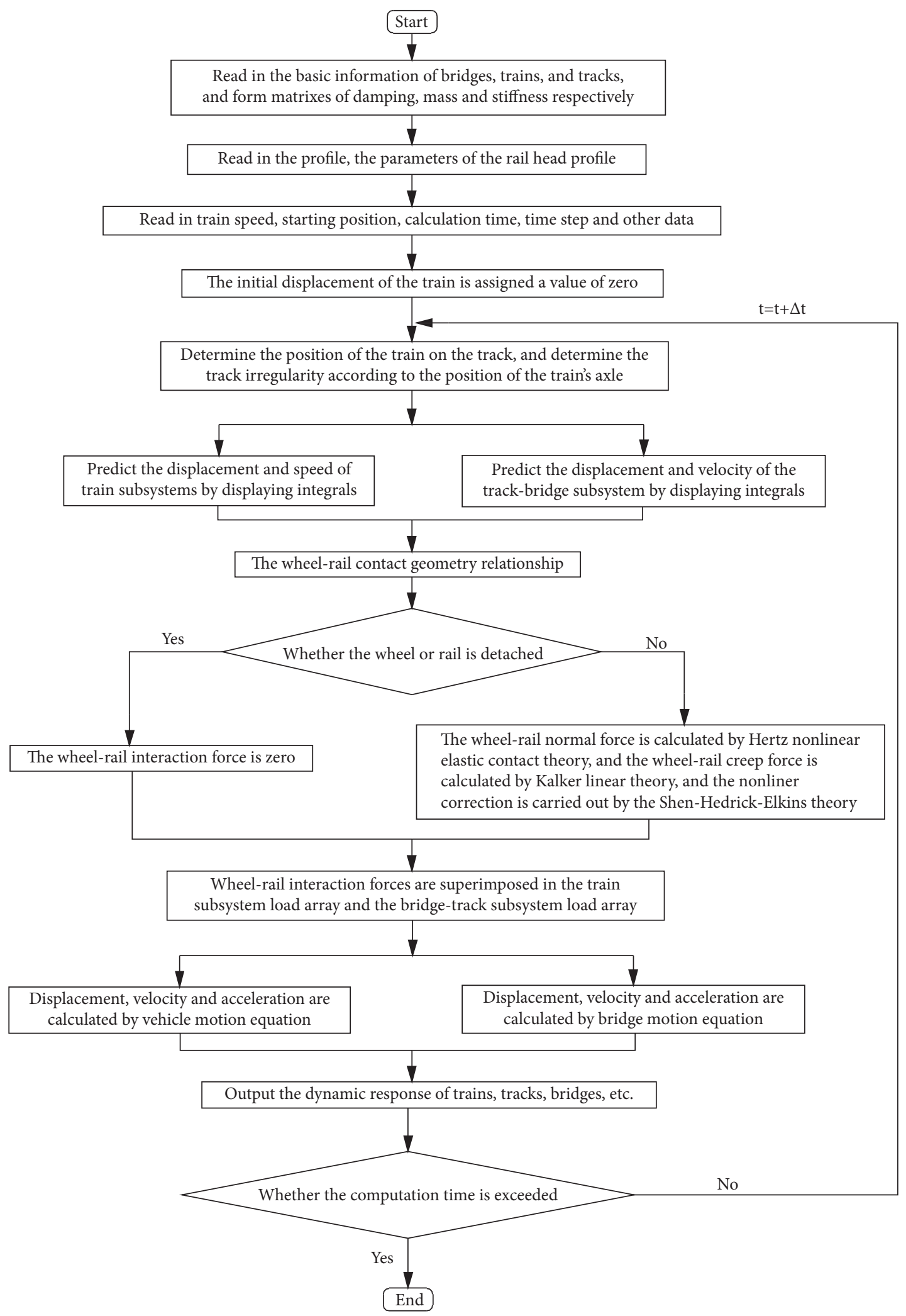

FIGURE 5: Block diagram of the dynamic analysis procedure for the coupled train-track-bridge system. 


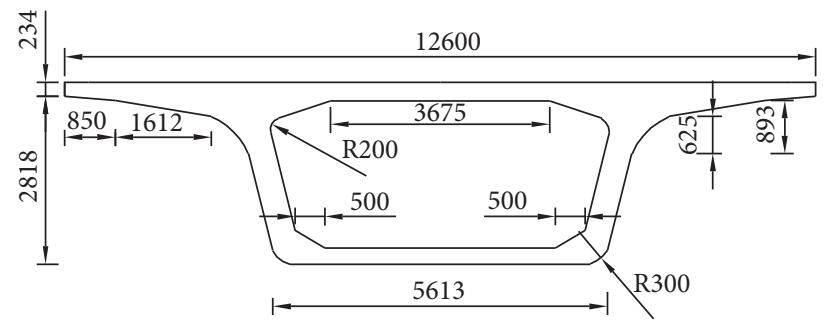

Figure 6: Cross-sectional view of the main beam (unit: $\mathrm{mm}$ ).

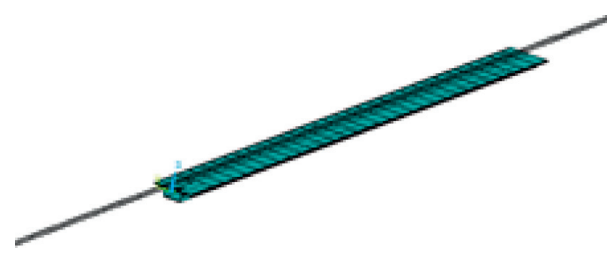

Figure 7: Bridge-track finite element model.

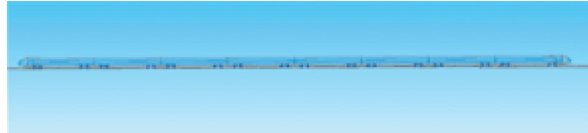

(a)

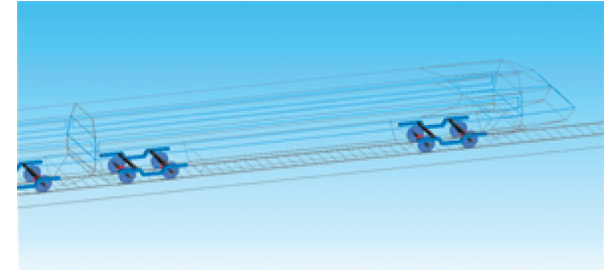

(b)

Figure 8: Train formation and single-section vehicle model in SIMPAK. (a) Train groupings. (b) Single-section vehicle model.

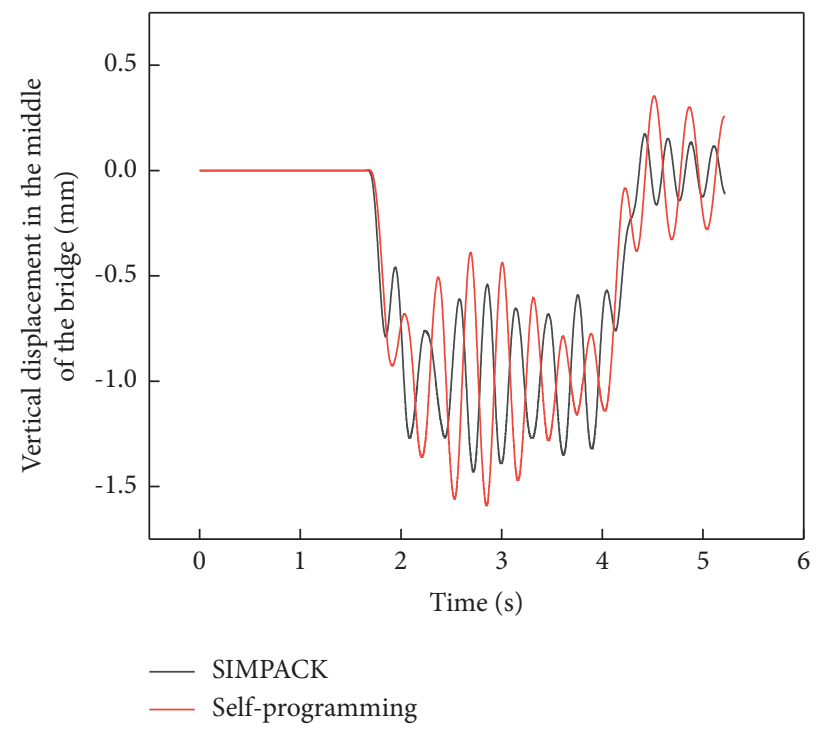

Figure 9: Comparison of vertical displacement times in span 3 of the bridge.

As can be seen from Table 4 and Figures 13 and 14, the section mass-shear heterocentric condition has a significant effect on the lateral displacement in the bridge span and a more pronounced effect on the lateral acceleration of the bridge than the bridge section mass-shear concentric condition but has less effect on the vertical and vehicle dynamic response in the bridge span.

In order to further study the influence of mass-shear heterocentricity of the main girder cross section on the coupled vibration law of high-speed railway simply 


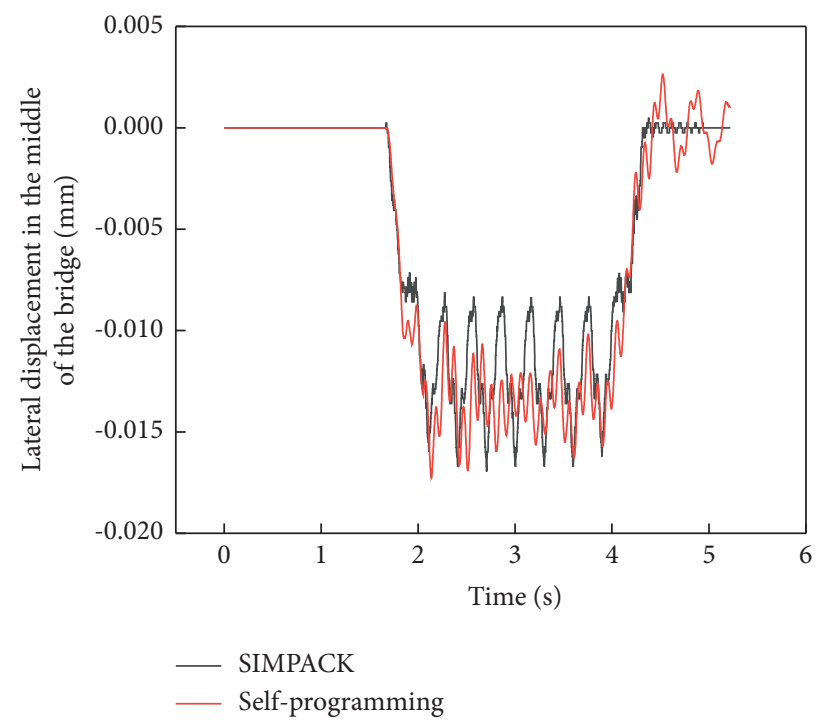

Figure 10: Comparison of the time course of lateral displacements in span 3 of the bridge.

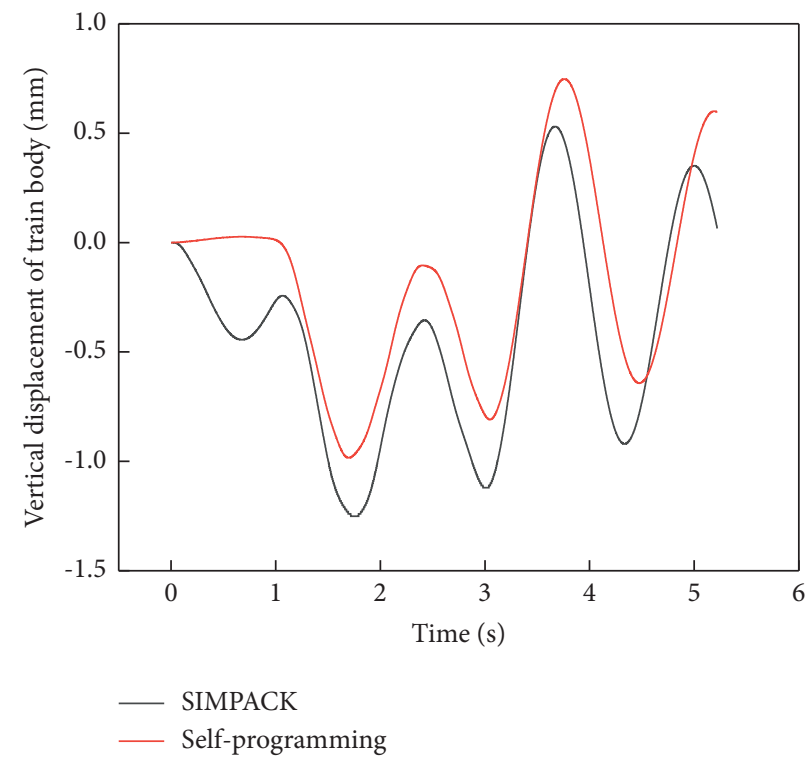

FIgURE 11: Comparison of the time course of the vertical displacement of the car body.

supported girder car and bridge, five common $32.6 \mathrm{~m}$-span double-line simply supported girder bridges in high-speed railway are simplified with equal cross sections. The main girder sections are shown in Figure 15, the section design parameters are shown in Tables 5 and 6 , and the section characteristic values are shown in Table 7.

In Table 7, $A$ is the area of the section; $A_{s y}$ and $A_{s z}$ are the shear areas in the $y$ - and $z$-directions of the section; $J$ is the torsional moment of inertia of the section; $I_{y y}$ and $I_{z z}$ are the moments of inertia of the section around the $y$ and $z$ axes; and $y_{c}$ and $z_{c}$ are the offset distances of the shear centre relative to the centre of mass in the centre-of-mass coordinate system. $A_{s y}$ and $A_{s z}$ are calculated with MIDAS software, and the remaining parameters are calculated using ANSYS.
From the section characteristic values in Table 7, it can be seen that for the main girder section of a common $32.6 \mathrm{~m}$ span double-line simply supported girder bridge for highspeed railways, the transverse offset distance of the massshear eccentricity ranges from -0.1605 to $0.01733 \mathrm{~mm}$ and its vertical offset distance ranges from -0.4743947 to $-0.3792095 \mathrm{~m}$.

To improve the efficiency of the calculation, a single span bridge is taken as an example, the main girder section is selected as girder section No. 5, and left line rails are laid on the bridge, in front of the bridge head and $15 \mathrm{~m}$ behind the bridge tail. A single trailer section is selected, and the rest of the parameters are the same as in the above example, simulating a train passing the bridge at constant speed. The dynamic response of the bridge is calculated using the 


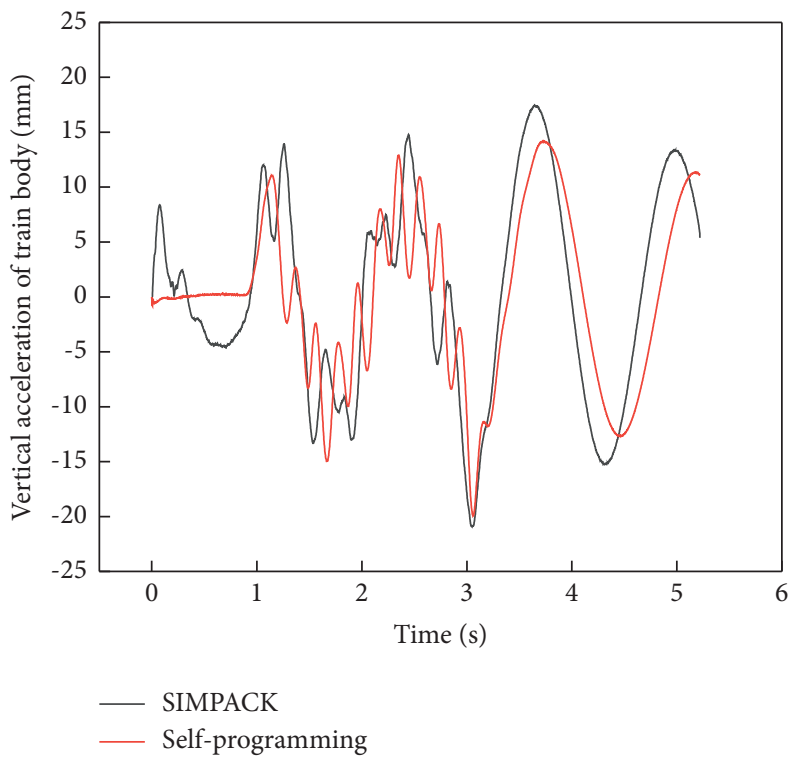

Figure 12: Comparison of the time course of the vertical acceleration of the vehicle body.

TABLE 4: Comparison of peak dynamic response of the axle.

\begin{tabular}{|c|c|c|c|c|}
\hline & ction & Response & $\begin{array}{l}\text { Different positions of the centre of mass and } \\
\text { shear }\end{array}$ & $\begin{array}{l}\text { The same position of the centre of mass and } \\
\text { shear }\end{array}$ \\
\hline \multirow{4}{*}{ Bridge } & \multirow[t]{2}{*}{ Horizontal } & $\begin{array}{l}\text { Displacement } \\
(\mathrm{mm})\end{array}$ & 0.0173 & 0.0280 \\
\hline & & Acceleration $\left(\mathrm{m} / \mathrm{s}^{2}\right)$ & 0.0205 & 0.0166 \\
\hline & \multirow[t]{2}{*}{ Vertical } & $\begin{array}{c}\text { Displacement } \\
(\mathrm{mm})\end{array}$ & 1.590 & 1.600 \\
\hline & & Acceleration $\left(\mathrm{m} / \mathrm{s}^{2}\right)$ & 0.285 & 0.291 \\
\hline \multirow{4}{*}{$\begin{array}{l}\text { Car } \\
\text { body }\end{array}$} & \multirow{2}{*}{ Horizontal } & $\begin{array}{l}\text { Displacement } \\
(\mathrm{mm})\end{array}$ & 0.0849 & 0.0843 \\
\hline & & Acceleration $\left(\mathrm{m} / \mathrm{s}^{2}\right)$ & 0.00436 & 0.00439 \\
\hline & \multirow[t]{2}{*}{ Vertical } & $\begin{array}{c}\text { Displacement } \\
(\mathrm{mm})\end{array}$ & 0.0984 & 0.0976 \\
\hline & & Acceleration $\left(\mathrm{m} / \mathrm{s}^{2}\right)$ & 0.0200 & 0.0198 \\
\hline
\end{tabular}

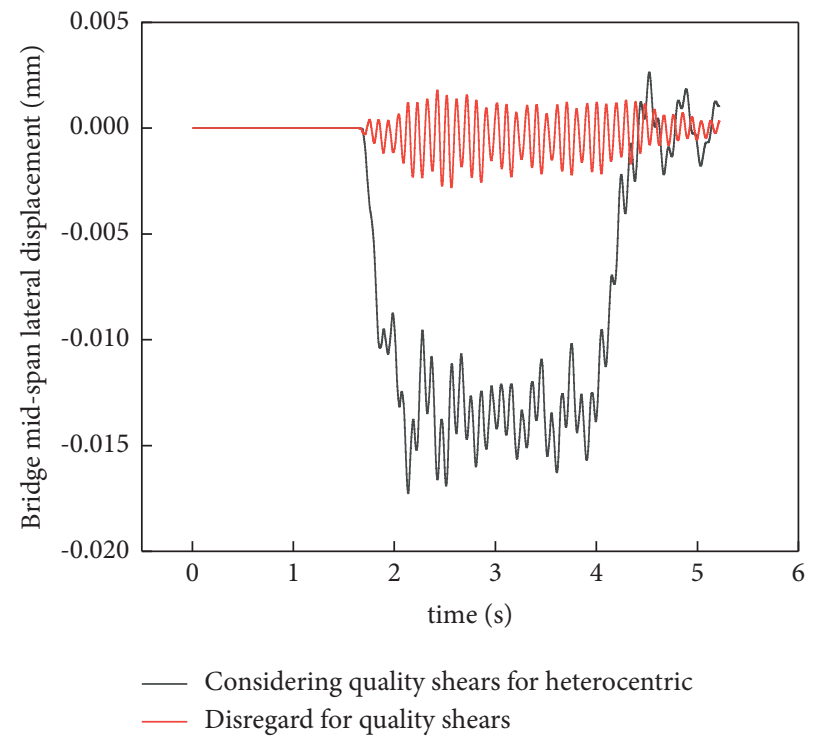

FIGURE 13: Comparison of the time course of lateral displacements in the span of the bridge. 


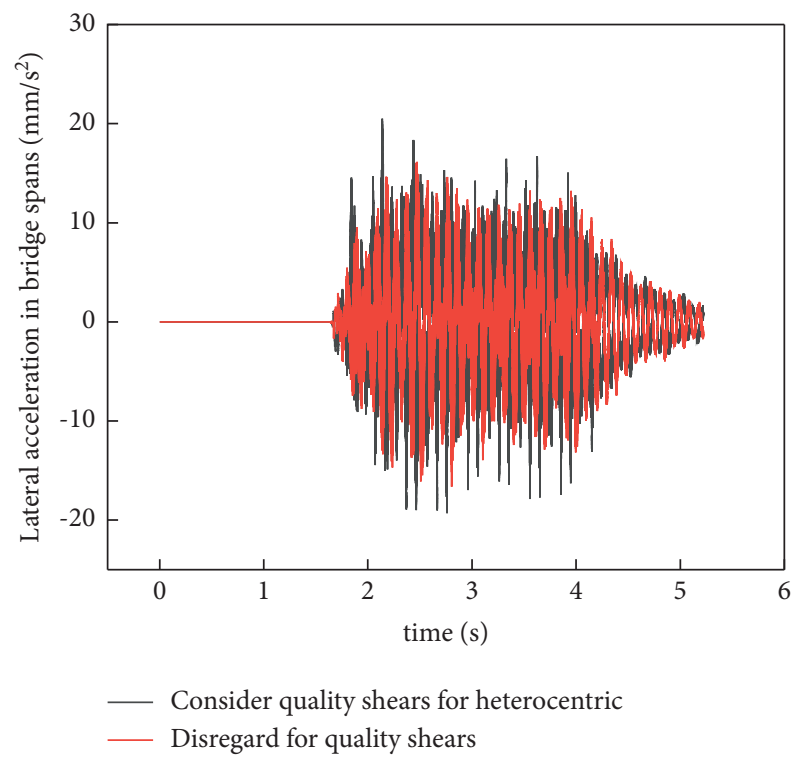

Figure 14: Comparison of the time course of lateral acceleration in the span of the bridge.

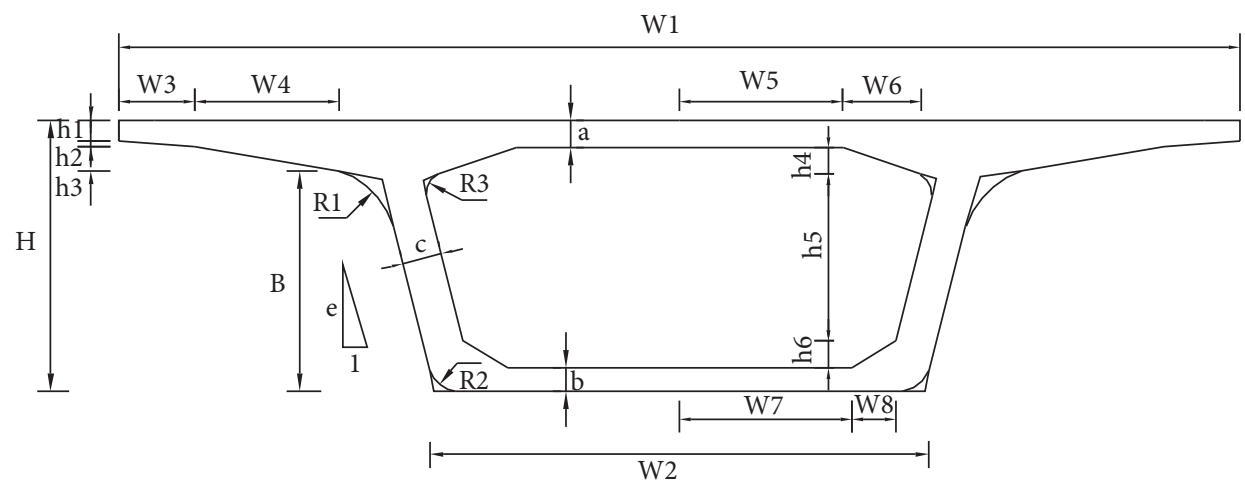

FIGURE 15: Cross-sectional drawing of a simply supported beam for a high-speed railway.

TABLE 5: Main design parameters of the cross section of a double-track simply supported box girder-1.

\begin{tabular}{|c|c|c|c|c|c|c|c|c|c|c|c|c|c|}
\hline $\begin{array}{l}\text { Bridge } \\
\text { type }\end{array}$ & Source & $\begin{array}{c}H \\
(\mathrm{~m})\end{array}$ & $B(\mathrm{~m})$ & $\begin{array}{c}h 1 \\
(\mathrm{~m})\end{array}$ & $\begin{array}{c}h 2 \\
(\mathrm{~m})\end{array}$ & $h 3(\mathrm{~m})$ & $\begin{array}{c}h 4 \\
(\mathrm{~m})\end{array}$ & $\begin{array}{l}h 5 \\
(\mathrm{~m})\end{array}$ & $\begin{array}{c}h 6 \\
(\mathrm{~m}) \\
\end{array}$ & $a(\mathrm{~m})$ & $\begin{array}{c}b \\
(\mathrm{~m})\end{array}$ & $\begin{array}{c}c \\
(\mathrm{~m})\end{array}$ & $\varepsilon$ \\
\hline 1 & Bridges (2008) 2322A-II & 3.05 & 2.4 & 0.284 & 0.044 & 0.35 & 0.35 & 1.82 & 0.3 & 0.3 & 0.28 & 0.45 & 4 \\
\hline $2[20]$ & $\begin{array}{l}\text { Simply supported box girder at } \\
350 \mathrm{~km} / \mathrm{h} \text { in Qin Shen }\end{array}$ & 3 & 2.3983 & 0.2 & 0.05 & 0.3517 & 0.35 & 1.8 & 0.3 & 0.34 & 0.3 & 0.47 & 5.1 \\
\hline 3 & Bridges (2016) 2321A-II-07 & 3.048 & 2.4 & 0.23 & 0.068 & 0.35 & 0.35 & 1.82 & 0.3 & 0.36 & 0.28 & 0.45 & 4 \\
\hline $4[20]$ & $\begin{array}{l}\text { Simply supported box girder at } \\
250 \mathrm{~km} / \mathrm{h} \text { in Qin Shen }\end{array}$ & 2.8 & 2.2246 & 0.29 & 0.05 & 0.35 & 0.35 & 1.6 & 0.3 & 0.34 & 0.3 & 0.47 & 5 \\
\hline 5 & Bridges (2016) 2322A-II-01 & 3.078 & 2.4 & 0.284 & 0.044 & 0.35 & 0.36 & 1.82 & 0.3 & 0.384 & 0.28 & 0.45 & 4 \\
\hline
\end{tabular}

procedure in this paper, where the bridge response is taken as the span centre and the train response is taken as the car body. The effect of parameters such as the mass-shear offset distance of the main girder section, the track centre offset distance, the car weight, and the car speed on the coupled vibration of the simply supported girder car and bridge of the high-speed railway is analyzed.
4.1. Influence of Mass-Shear Offset Distance of the Main Beam Section. Keeping the other parameters of the section unchanged, the transverse distance of the shear centre from the centre of mass is increased in the proportion of $0 \%, 30 \%$, $50 \%, 80 \%$, and $100 \%$, i.e., $0.00 \mathrm{~mm},-0.04815 \mathrm{~mm}$, $-0.08025 \mathrm{~mm},-0.1284 \mathrm{~mm}$, and $-0.1605 \mathrm{~mm}$ in order. 5 working conditions are defined, the axle dynamic response is 
TABLE 6: Main design parameters of the cross section of a double-track simply supported box girder-2.

\begin{tabular}{|c|c|c|c|c|c|c|c|c|c|c|c|c|}
\hline $\begin{array}{l}\text { Bridge } \\
\text { type }\end{array}$ & Source & $\begin{array}{l}W 1 \\
(\mathrm{~m})\end{array}$ & $\begin{array}{l}W 2 \\
(\mathrm{~m})\end{array}$ & $\begin{array}{l}W 3 \\
(\mathrm{~m})\end{array}$ & $\begin{array}{l}W 4 \\
(\mathrm{~m})\end{array}$ & $\begin{array}{l}W 5 \\
(\mathrm{~m})\end{array}$ & $\begin{array}{l}\text { W6 } \\
(\mathrm{m})\end{array}$ & $\begin{array}{l}W 7 \\
(\mathrm{~m})\end{array}$ & $\begin{array}{l}W 8 \\
(\mathrm{~m})\end{array}$ & $R 1$ & $R 2$ & $R 3$ \\
\hline 1 & Bridges (2008) 2322A-II & 12 & 5.5 & 0.55 & 2.10 & 1.836 & 1.05 & 1.931 & 0.5 & 0.75 & 0.3 & 0.2 \\
\hline 2 & $\begin{array}{l}\text { Simply supported box girder at } 350 \mathrm{~km} / \\
\mathrm{h} \text { in Qin Shen }\end{array}$ & 13.4 & 5.74 & 1.2502 & 2.11 & 1.820 & 1.05 & 2.2067 & 0.3 & 0.7 & 0.3 & 0.2 \\
\hline 3 & Bridges (2016) 2321A-II-07 & 12.6 & 5.5 & 0.8554 & 2.10 & 1.836 & 1.05 & 1.931 & 0.5099 & 0.75 & 0.3 & 0.2 \\
\hline 4 & $\begin{array}{l}\text { Simply supported box girder at } 250 \mathrm{~km} / \\
\mathrm{h} \text { in Qin Shen }\end{array}$ & 13 & 5.52 & 1.2005 & 2.10 & 1.670 & 1.05 & 2.097 & 0.303 & 0.7 & 0.3 & 0.2 \\
\hline 5 & Bridges (2016) 2322A-II-01 & 12 & 5.5 & 0.55 & 2.10 & 1.836 & 1.05 & 1.931 & 0.5 & 0.75 & 0.3 & 0.2 \\
\hline
\end{tabular}

TABLE 7: Cross-sectional characteristic values for the double-track simply supported box girder.

\begin{tabular}{lcccccccccc}
\hline $\begin{array}{l}\text { Bridge } \\
\text { type }\end{array}$ & Source & $A$ & $A_{s y}$ & $A_{s z}$ & $J$ & $I_{y y}$ & $I_{z z}$ & $y_{c}$ & $z_{c}$ \\
\hline 1 & Bridges (2008) 2322A-II & 8.96019 & 5.40742 & 2.14232 & 23.3145 & 11.0043 & 84.7012 & 0.0000158 & -0.4743947 \\
2 & Simply supported box girder at 350 km/h & 9.02845 & 5.74332 & 2.09189 & 23.9362 & 11.1949 & 90.0468 & 0.0000652 & -0.4128688 \\
3 & in Qin Shen & Bridges (2016) 2321A-II-07 & 8.95864 & 5.65958 & 2.10657 & 23.7511 & 10.9725 & 85.435 & 0.00001733 & -0.4015341 \\
4 & Simply supported box girder at 250 km/h & 8.6648 & 5.61904 & 1.94309 & 19.98 & 9.19981 & 80.8044 & -0.00000918 & -0.3878478 \\
5 & in Qin Shen & Bridges (2016) 2322A-II-01 & 9.13025 & 5.73274 & 2.13657 & 24.616 & 11.2494 & 84.6348 & -0.0001605 & -0.3792095 \\
\hline
\end{tabular}

calculated, and the peak values of axle displacement and acceleration response are obtained. The peak values of the acceleration response are shown in Table 8.

As can be seen from the data in Table 8, the peak displacements and accelerations of the bridge and car body do not change much as the transverse distance between the shear centre of the bridge section and the centre of mass gradually increases. Box girder sections in practical engineering are usually symmetrical about the vertical axis, and the transverse distance between the shear centre and the centre of mass is generally small and its effect on the dynamic response of the bridge is also small.

Keeping the other parameters of the section constant, the vertical distance of the shear centre from the centre of mass was increased in the order of 1.0 times, 1.1 times, 1.15 times, 1.2 times, and 1.25 times, i.e., taking the following order: $-0.37921 \mathrm{~m},-0.41713 \mathrm{~m},-0.43609 \mathrm{~m},-0.45505 \mathrm{~m}$, and $-0.47401 \mathrm{~m}$. Five operating conditions are defined, the axle power response is calculated, and the peak value of the axle response is obtained as shown in Table 9.

From the data in Table 9, it can be seen that as the vertical distance between the shear centre of the bridge section and the centre of mass increases, the lateral displacement and acceleration of the bridge show a monotonic increasing trend, while the vertical response of the bridge and the peak dynamic response of the vehicle body do not change significantly. The peak transverse displacement of the bridge increases from $0.00714 \mathrm{~mm}$ to $0.00916 \mathrm{~mm}$, an increase of 28.3\%; the peak transverse acceleration of the bridge increases from $0.0145 \mathrm{~m} / \mathrm{s}^{2}$ to $0.0191 \mathrm{~m} / \mathrm{s}^{2}$, an increase of $31.72 \%$, indicating that the vertical offset distance of the shear centre of the main girder section has a significant effect on the transverse displacement of the bridge.
4.2. Influence of the Track Centre Line Offset Distance. In the case of high-speed railways simply supported girders, the track centre line of a two-line railway is usually offset from the bridge centre line by a distance of $2.5 \mathrm{~m}$, while the centre line of a single-line railway often overlaps with the bridge centre line. In order to study the influence of the transverse offset distance of the track centre line, the other parameters in the bridge-track model are kept constant and only the transverse offset distance between the track centre line and the bridge centre line is changed to $0.0 \mathrm{~m}, 1.0 \mathrm{~m}, 1.5 \mathrm{~m}, 2.0 \mathrm{~m}$, and $2.5 \mathrm{~m}$, respectively. Five operating conditions are defined, the axle power response is calculated, and the peak values of the axle response are obtained as shown in Table 10.

From the data in Table 10, it can be seen that with the increase of the lateral offset distance between the track centre line and the bridge centre line, the peak value of the car body lateral displacement is monotonically decreasing, the peak value of the bridge lateral displacement and acceleration and the peak value of the car body lateral acceleration are monotonically increasing, and the peak value of the bridge vertical displacement reaches the minimum value under working condition 3 . The peak transverse displacement of the bridge increased from $0.00153 \mathrm{~mm}$ to $0.00714 \mathrm{~mm}$, an increase of $78.6 \%$; the peak transverse acceleration of the bridge increased from $0.00590 \mathrm{~m} / \mathrm{s}^{2}$ to $0.0145 \mathrm{~m} / \mathrm{s}^{2}$, an increase of $59 \%$; the peak transverse displacement of the car body decreased from $0.324 \mathrm{~mm}$ to $0.306 \mathrm{~mm}$, a decrease of $5.9 \%$. This indicates that the distance of the lateral offset of the track centre line has a significant effect on the dynamic response of the bridge, while the effect on the car body is smaller.

As the height of the bridge section changes, the vertical distance between the mass centre of the track unit and the mass centre of the bridge section will change. In the case of a 
TABLE 8: Peak axle displacements and acceleration under different mass-shear lateral offset distance operating conditions.

\begin{tabular}{|c|c|c|c|c|c|c|c|c|c|c|c|}
\hline \multirow{2}{*}{\multicolumn{2}{|c|}{ Direction }} & \multicolumn{5}{|c|}{ Displacement (m) } & \multicolumn{5}{|c|}{ Acceleration $\left(\mathrm{m} / \mathrm{s}^{2}\right)$} \\
\hline & & Mode 1 & Mode 2 & Mode 3 & Mode 4 & Mode 5 & Mode 1 & Mode 2 & Mode 3 & Mode 4 & Mode 5 \\
\hline \multirow{2}{*}{ Bridge } & Horizontal & $7.09 E-06$ & $7.10 E-06$ & $7.03 E-06$ & $7.21 E-06$ & $7.14 E-06$ & $1.54 E-02$ & $1.44 E-02$ & $1.46 E-02$ & $1.46 E-02$ & $1.45 E-02$ \\
\hline & Vertical & $7.32 E-04$ & $7.31 E-04$ & $7.31 E-04$ & $7.31 E-04$ & $7.31 E-04$ & $2.35 E-01$ & $2.34 E-01$ & $2.34 E-01$ & $2.35 E-01$ & $2.36 E-01$ \\
\hline \multirow{2}{*}{$\begin{array}{l}\text { Car } \\
\text { body }\end{array}$} & Horizontal & $3.06 E-04$ & $3.06 E-04$ & $3.06 E-04$ & $3.06 E-04$ & $3.06 E-04$ & $1.56 E-02$ & $1.56 E-02$ & $1.56 E-02$ & $1.56 E-02$ & $1.56 E-02$ \\
\hline & Vertical & $6.24 E-04$ & $6.24 E-04$ & $6.24 E-04$ & $6.24 E-04$ & $6.24 E-04$ & $3.23 E-02$ & $3.23 E-02$ & $3.23 E-02$ & $3.23 E-02$ & $3.23 E-02$ \\
\hline
\end{tabular}

Table 9: Peak axle displacements and acceleration under different mass-shear vertical offset distance operating conditions.

\begin{tabular}{|c|c|c|c|c|c|c|c|c|c|c|c|}
\hline \multirow{2}{*}{\multicolumn{2}{|c|}{ Direction }} & \multicolumn{5}{|c|}{ Displacement (m) } & \multicolumn{5}{|c|}{ Acceleration $\left(\mathrm{m} / \mathrm{s}^{2}\right)$} \\
\hline & & Mode 1 & Mode 2 & Mode 3 & Mode 4 & Mode 5 & Mode 1 & Mode 2 & Mode 3 & Mode 4 & Mode 5 \\
\hline \multirow{2}{*}{ Bridge } & Horizontal & $7.14 E-06$ & $7.91 E-06$ & $8.29 E-06$ & $8.74 E-06$ & $9.16 E-06$ & $1.45 E-02$ & $1.60 E-02$ & $1.70 E-02$ & $1.79 E-02$ & $1.91 E-02$ \\
\hline & Vertical & $7.31 E-04$ & $7.32 E-04$ & $7.31 E-04$ & $7.32 E-04$ & $7.32 E-04$ & $2.36 E-01$ & $2.34 E-01$ & $2.34 E-01$ & $2.35 E-01$ & $2.34 E-01$ \\
\hline \multirow{2}{*}{$\begin{array}{l}\text { Car } \\
\text { body }\end{array}$} & Horizontal & $3.06 E-04$ & $3.06 E-04$ & $3.06 E-04$ & $3.06 E-04$ & $3.06 E-04$ & $1.56 E-02$ & $1.56 E-02$ & $1.56 E-02$ & $1.56 E-02$ & $1.55 E-02$ \\
\hline & Vertical & $6.24 E-04$ & $6.25 E-04$ & $6.24 E-04$ & $6.25 E-04$ & $6.25 E-04$ & $3.23 E-02$ & $3.23 E-02$ & $3.23 E-02$ & $3.23 E-02$ & $3.23 E-02$ \\
\hline
\end{tabular}

TABLE 10: Peak axle displacements and acceleration under different track centre line lateral offset distance operating conditions.

\begin{tabular}{|c|c|c|c|c|c|c|c|c|c|c|c|}
\hline \multirow{2}{*}{\multicolumn{2}{|c|}{ Direction }} & \multicolumn{5}{|c|}{ Displacement (m) } & \multicolumn{5}{|c|}{ Acceleration $\left(\mathrm{m} / \mathrm{s}^{2}\right)$} \\
\hline & & Mode 1 & Mode 2 & Mode 3 & Mode 4 & Mode 5 & Mode 1 & Mode 2 & Mode 3 & Mode 4 & Mode 5 \\
\hline \multirow{2}{*}{ Bridge } & Horizontal & $1.53 E-06$ & $2.76 E-06$ & $4.16 E-06$ & $5.91 E-06$ & $7.14 E-06$ & $5.90 E-03$ & $7.80 E-03$ & $1.03 E-02$ & $1.35 E-02$ & $1.45 E-02$ \\
\hline & Vertical & $7.15 E-04$ & $6.86 E-04$ & $6.82 E-04$ & $7.18 E-04$ & $7.31 E-04$ & $3.43 E-01$ & $3.08 E-01$ & $2.82 E-01$ & $2.87 E-01$ & $2.36 E-01$ \\
\hline \multirow{2}{*}{$\begin{array}{l}\text { Car } \\
\text { body }\end{array}$} & Horizontal & $3.24 E-04$ & $3.22 E-04$ & $3.18 E-04$ & $3.12 E-04$ & $3.06 E-04$ & $1.42 E-02$ & $1.45 E-02$ & $1.50 E-02$ & $1.54 E-02$ & $1.56 E-02$ \\
\hline & Vertical & $5.81 E-04$ & $5.79 E-04$ & $5.89 E-04$ & $6.11 E-04$ & $6.24 E-04$ & $3.25 E-02$ & $3.22 E-02$ & $3.18 E-02$ & $3.19 E-02$ & $3.23 E-02$ \\
\hline
\end{tabular}

bridge main girder section with mass-shear eccentricity, the other parameters in the bridge-track model are kept unchanged and only the vertical offset distance between the mass centre of the track unit and the mass centre of the bridge section is changed, with the values taken as 1.0, 1.1, $1.15,1.2$, and 1.25 times of $1.05 \mathrm{~m}$, i.e., $1.05 \mathrm{~m}, 1.155 \mathrm{~m}$, $1.2075 \mathrm{~m}, 1.26 \mathrm{~m}$, and $1.3125 \mathrm{~m}$, respectively, according to the range of bridge section height variation. Defining five operating conditions, the axle power response was calculated and the peak values of the axle response were obtained as shown in Table 11.

From the data in Table 11, it can be seen that as the vertical offset distance between the track centre of mass and the bridge centre of mass increases, the peak transverse displacement and acceleration of the bridge show a monotonic increasing trend and the peak vertical displacement of the bridge reaches its maximum value under working condition 3 . The peak dynamic response of the car body does not change significantly. The peak transverse displacement of the bridge increased from $0.00714 \mathrm{~mm}$ to $0.00735 \mathrm{~mm}$, an increase of $3 \%$; the peak transverse acceleration of the bridge increased from $0.0145 \mathrm{~m} / \mathrm{s}^{2}$ to $0.0183 \mathrm{~m} /$ $\mathrm{s}^{2}$, an increase of $26 \%$; this indicates that the distance of the vertical offset of the track centre has a significant effect on the dynamic response of the bridge.

4.3. Influence of Vehicle Weight. The wheel weights transferred to the track contact point by a single wheel of a common model of a high-speed train range from $58836 \mathrm{~N}$ to $78448 \mathrm{~N}$. Under the consideration of the mass-shear eccentricity of the bridge main girder section, keeping other parameters unchanged and changing only the single wheel weight of the train, the values are taken as 0.6 times, 0.7 times, 0.8 times, 0.9 times, and 1.0 times of $78448 \mathrm{~N}$, i.e., $47068.8 \mathrm{~N}, 54913.6 \mathrm{~N}, 62758.4 \mathrm{~N}, 70603.2 \mathrm{~N}$, and $78448 \mathrm{~N}$. Five operating conditions were defined, the axle power response was calculated, and the peak values of the axle response were obtained as shown in Table 12.

As can be seen from the data in Table 12, with the increase in vehicle weight, the peak dynamic response of both the bridge and the vehicle body monotonically increased, with the peak vertical displacement of the bridge increasing from $0.481 \mathrm{~mm}$ to $0.801 \mathrm{~mm}$, an increase of $40 \%$; the peak vertical displacement of the track increasing from $0.713 \mathrm{~mm}$ to $1.17 \mathrm{~mm}$, an increase of $39 \%$; and the peak vertical displacement of the vehicle body increasing from $0.431 \mathrm{~mm}$ to $0.720 \mathrm{~mm}$, an increase of $40 \%$; this indicates that the weight of the car has a significant effect on the dynamic response of the axle.

4.4. Influence of Vehicle Speed. Under the consideration of the bridge main girder section mass-shear heterocentric condition, keeping other parameters unchanged, the speeds of $250 \mathrm{~km} / \mathrm{h}, 280 \mathrm{~km} / \mathrm{h}, 300 \mathrm{~km} / \mathrm{h}, 320 \mathrm{~km} / \mathrm{h}$, and $350 \mathrm{~km} / \mathrm{h}$ respectively, are chosen. Five working conditions are defined, the axle dynamic response is calculated, and the peak of the axle response is obtained as shown in Table 13.

From the data in Table 13, it can be seen that with the increase in vehicle speed, the vertical displacement of the bridge shows a monotonic increasing trend, the peak of the horizontal and vertical displacement of the car body shows a monotonic decreasing trend, and the peak of the horizontal 
TABLE 11: Peak axle displacements and acceleration under different track centre line vertical offset distance operating conditions.

\begin{tabular}{|c|c|c|c|c|c|c|c|c|c|c|c|}
\hline \multirow{2}{*}{\multicolumn{2}{|c|}{ Direction }} & \multicolumn{5}{|c|}{ Displacement (m) } & \multicolumn{5}{|c|}{ Acceleration $\left(\mathrm{m} / \mathrm{s}^{2}\right)$} \\
\hline & & Mode 1 & Mode 2 & Mode 3 & Mode 4 & Mode 5 & Mode 1 & Mode 2 & Mode 3 & Mode 4 & Mode 5 \\
\hline \multirow{2}{*}{ Bridge } & Horizontal & $7.14 E-06$ & $7.22 E-06$ & $7.23 E-06$ & $7.34 E-06$ & $7.35 E-06$ & $1.45 E-02$ & $1.52 E-02$ & $1.60 E-02$ & $1.74 E-02$ & $1.83 E-02$ \\
\hline & Vertical & $7.31 E-04$ & $7.36 E-04$ & $7.38 E-04$ & $7.34 E-04$ & $7.32 E-04$ & $2.36 E-01$ & $2.32 E-01$ & $2.31 E-01$ & $2.32 E-01$ & $2.32 E-01$ \\
\hline \multirow{2}{*}{$\begin{array}{l}\text { Car } \\
\text { body }\end{array}$} & Horizontal & $3.06 E-04$ & $3.05 E-04$ & $3.05 E-04$ & $3.05 E-04$ & $3.04 E-04$ & $1.56 E-02$ & $1.56 E-02$ & $1.56 E-02$ & $1.56 E-02$ & $1.56 E-02$ \\
\hline & Vertical & $6.24 E-04$ & $6.26 E-04$ & $6.27 E-04$ & $6.24 E-04$ & $6.23 E-04$ & $3.23 E-02$ & $3.23 E-02$ & $3.24 E-02$ & $3.23 E-02$ & $3.23 E-02$ \\
\hline
\end{tabular}

TABLE 12: Peak axle displacements and acceleration under different vehicle weight operating conditions.

\begin{tabular}{|c|c|c|c|c|c|c|c|c|c|c|c|}
\hline \multirow{2}{*}{\multicolumn{2}{|c|}{ Direction }} & \multicolumn{5}{|c|}{ Displacement (m) } & \multicolumn{5}{|c|}{ Acceleration $\left(\mathrm{m} / \mathrm{s}^{2}\right)$} \\
\hline & & Mode 1 & Mode 2 & Mode 3 & Mode 4 & Mode 5 & Mode 1 & Mode 2 & Mode 3 & Mode 4 & Mode 5 \\
\hline \multirow{2}{*}{ Bridge } & Horizontal & $4.69 E-06$ & $5.47 E-06$ & $6.23 E-06$ & $7.01 E-06$ & $7.79 E-06$ & $1.07 E-02$ & $1.14 E-02$ & $1.25 E-02$ & $1.43 E-02$ & $1.53 E-02$ \\
\hline & Vertical & $4.81 E-04$ & $5.61 E-04$ & $6.41 E-04$ & $7.21 E-04$ & $8.01 E-04$ & $1.61 E-01$ & $1.84 E-01$ & $2.08 E-01$ & $2.31 E-01$ & $2.54 E-01$ \\
\hline \multirow{2}{*}{$\begin{array}{l}\text { Car } \\
\text { body }\end{array}$} & Horizontal & $2.87 E-04$ & $2.94 E-04$ & $2.98 E-04$ & $3.01 E-04$ & $3.03 E-04$ & $1.10 E-02$ & $1.20 E-02$ & $1.30 E-02$ & $1.39 E-02$ & $1.47 E-02$ \\
\hline & Vertical & $3.51 E-04$ & $4.31 E-04$ & $5.21 E-04$ & $6.20 E-04$ & $7.20 E-04$ & $1.95 E-02$ & $2.43 E-02$ & $2.90 E-02$ & $3.36 E-02$ & $3.81 E-02$ \\
\hline
\end{tabular}

TABLe 13: Peak axle displacements and acceleration under different vehicle speed operating conditions.

\begin{tabular}{|c|c|c|c|c|c|c|c|c|c|c|c|}
\hline \multirow{2}{*}{\multicolumn{2}{|c|}{ Direction }} & \multicolumn{5}{|c|}{ Displacement (m) } & \multicolumn{5}{|c|}{ Acceleration $\left(\mathrm{m} / \mathrm{s}^{2}\right)$} \\
\hline & & Mode 1 & Mode 2 & Mode 3 & Mode 4 & Mode 5 & Mode 1 & Mode 2 & Mode 3 & Mode 4 & Mode 5 \\
\hline \multirow{2}{*}{ Bridge } & Horizontal & $7.69 E-06$ & $7.77 E-06$ & $7.79 E-06$ & $7.80 E-06$ & $7.78 E-06$ & $1.49 E-02$ & $1.63 E-02$ & $1.53 E-02$ & $1.73 E-02$ & $2.08 E-02$ \\
\hline & Vertical & $7.52 E-04$ & $7.81 E-04$ & $8.01 E-04$ & $8.16 E-04$ & $8.33 E-04$ & $2.29 E-01$ & $2.70 E-01$ & $2.54 E-01$ & $2.87 E-01$ & $2.61 E-01$ \\
\hline \multirow{2}{*}{$\begin{array}{l}\text { Car } \\
\text { body }\end{array}$} & Horizontal & $4.31 E-04$ & $3.55 E-04$ & $3.03 E-04$ & $2.63 E-04$ & $2.20 E-04$ & $1.09 E-02$ & $1.39 E-02$ & $1.47 E-02$ & $1.49 E-02$ & $1.42 E-02$ \\
\hline & Vertical & $7.69 E-06$ & $7.77 E-06$ & $7.79 E-06$ & $7.80 E-06$ & $7.78 E-06$ & $1.49 E-02$ & $1.63 E-02$ & $1.53 E-02$ & $1.73 E-02$ & $2.08 E-02$ \\
\hline
\end{tabular}

displacement and vertical acceleration of the bridge reaches the maximum under working condition 4 . The peak vertical displacement of the bridge increases from $0.752 \mathrm{~mm}$ to $0.833 \mathrm{~mm}$, an increase of $10 \%$. The peak vertical displacement of the track increases from $1.11 \mathrm{~mm}$ to $1.19 \mathrm{~mm}$, an increase of $7 \%$. The peak vertical displacement of the car body decreases from $0.749 \mathrm{~mm}$ to $0.702 \mathrm{~mm}$, a reduction of $6 \%$.

Of these factors, the main girder section mass-shear vertical eccentricity distance, the track centreline lateral offset distance, and the vehicle weight are the main influencing factors for the lateral dynamic response in the span of the bridge.

\section{Conclusion}

(1) When considering the mass-shear eccentricity of a beam unit section, the torsional effect affects the lateral and vertical degrees of freedom of the unit, with the lateral and vertical stiffness of the beam unit being proportional to the vertical and lateral distances of the mass-shear eccentricity of the section, respectively.

(2) Through example verification, the calculation results of this paper's self-programmed program and SIMPACK software basically match, indicating that this paper's program can be used for the coupled vibration analysis of railway bridge cars and bridges.

(3) In common simple girder bridges for high-speed railways, the mass-shear heterocentricity of the main girder section has a significant effect on the lateral dynamic response of the bridge span, while the effect on the vertical and car dynamic response of the bridge span is smaller.

(4) Within the range of mass-shear offset distance of the main girder section of the actual project, the massshear transverse offset has a small effect on the dynamic response of the bridge, while the massshear vertical offset has a significant effect on the transverse dynamic response of the bridge. The maximum variation of the peak transverse displacement in the bridge span is $28.3 \%$, and the maximum variation of the peak transverse acceleration in the bridge span is $31.72 \%$; the influence of the track centre offset on the bridge and track dynamic response is more significant. The effect on the response of the car body is less significant, where the lateral offset of the track centre has a greater effect on the lateral dynamic response of the bridge than the vertical offset distance, with a maximum variation of $78.6 \%$ in the peak lateral displacement and 59\% in the peak lateral acceleration of the bridge span; the peak dynamic response of the bridge, track, and car body increases monotonically with increasing wheel weights for different vehicle types. The maximum variation of the peak dynamic response of the bridge and the car body is $40 \%$ and $51 \%$, respectively, when considering the mass-shear heterocentricity of the bridge main girder section within the range of common wheel weights; at common train speeds and 
considering the mass-shear heterocentricity of the bridge main girder section, the vertical displacement of the bridge tends to increase monotonically with increasing speed and the peak horizontal and vertical displacement of the car body tends to decrease monotonically. The peak acceleration of the bridge and vehicle body reaches a maximum at a certain speed.

\section{Data Availability}

The data used to support the findings of this study are included within the article.

\section{Conflicts of Interest}

The authors declare that they have no conflicts of interest.

\section{Acknowledgments}

This study was supported by the National Natural Science Foundation of China (51408557), the China Postdoctoral Science Foundation Project (2013M541995), and the Henan Provincial Transportation Technology Project (2020J-2-6).

\section{References}

[1] X. C. Wang, Finite Element Method, Tsinghua University Press, Beijing, China, 2003.

[2] S. S. Eshkevari, T. J. Matarazzo, and S. N. Pakzad, "Simplified vehicle-bridge interaction for medium to long-span bridges subject to random traffic load," Journal of Civil Structural Health Monitoring, vol. 10, no. 4, pp. 693-707, 2020.

[3] X. Z. Li and S. Z. Qiang, "State-of-the-art review and trend of studies on vehicle-bridge interaction," Journal of the China Railway Society, vol. 24, no. 5, pp. 112-120, 2002.

[4] X. L. Zheng, X. Y. Xu, K. J. Chen et al., "Deformation control limit of long-span concrete arch bridge of high-speed railway," China Railway Science, vol. 40, no. 3, pp. 60-64, 2019.

[5] Z. H. Zhu, L. D. Wang, L. Yang et al., "Effect of short-wave component in rail irregularity on the coupled dynamic responses of train and simpl-supported bridge," Journal of Hunan University, vol. 43, no. 1, pp. 53-60, 2016.

[6] H. Gou, C. Liu, W. Zhou, Y. Bao, and Q. Pu, "Dynamic responses of a high-speed train passing a deformed bridge using a vehicle-track-bridge coupled model," Proceedings of the Institution of Mechanical Engineers - Part F: Journal of Rail and Rapid Transit, vol. 235, no. 4, pp. 463-477, 2020.

[7] W. Liu and W. Guo, "Vibration analysis of EMS-Type maglev vehicles traveling over a long-span bridge with double lines," Ksce journal of civil engineering, vol. 24, no. 5, pp. 1531-1544, 2020.

[8] Z. Xu, Z. Du, Z. Yang, and J. Zhou, "Research on vehiclebridge vertical coupling dynamics of monorail based on multiple road excitations," Mechanics, vol. 26, no. 4, pp. 301-310, 2020.

[9] Y. Bao, H. Xiang, and Y. Li, “A dynamic analysis scheme for the suspended monorail vehicle-curved bridge coupling system," Advances in Structural Engineering, vol. 23, no. 8, pp. 1728-1738, 2020.

[10] G. T. Shi, J. J. Yang, X. W. Yang et al., "Vetical vetical-trackbridge coupling vibration based on dynamic flexibility method," Journal of Central South University, vol. 48, no. 4, pp. 1119-1126, 2017.

[11] Q. Gao, K. Cui, Z. Li, and Y. Li, "Numerical investigation of the dynamic performance and riding comfort of a straddletype monorail subjected to moving trains," Applied Sciences, vol. 10, no. 15, p. 5258, 2020.

[12] H. R. Xie, B. Yan, and J. Huang, "Vertical dynamic analysis of ballastless tracks on train-track-bridge system," MATEC web of conferences, vol. 306, 2020.

[13] Z. G. Wang and X. Y. Li, "Analysis for vehicle-track-bridge coupling vibration of simply supported box-girder and U-girder," Journal of Railway Science and Engineering, vol. 15, no. 4, pp. 933-941, 2018.

[14] Y. H. Zhang, "Flexural torsional finite element analysis of thin-walled box girders," China Civil Engineering Journal, vol. 28 , no. 6, pp. 28-36, 2017.

[15] D. H. Chen, Research on Vibration Control of Dynamic Responses for Vehicle-Bridge System under Earthquakes, Central South University, Changsha, China, 2011.

[16] X. B. Zhou and R. B. Chen, "An element stiffness matrix of thin-walled open cross section bar in the centroid coordin"tes," Journal of Harbin University of Civil Engineering and Architecture, vol. 1, pp. 65-77, 1987.

[17] W. M. Zhai and S. L. Wang, "Influence of bridge structural stiffness on dynamic performance of high-speed train-trackbridge coupled system," China Railway Science, vol. 33, no. 1, pp. 19-26, 2012.

[18] C. Q. Xiang, Study on Dynamic Response of Coupled System of Train-Track-Bridge under strong Crosswind and Optimal Parameters of Wind Barriers, Central South University, Changsha, China, 2015.

[19] Y. Zhou, Simulation Analysis of Railway Vehicle Bridge Coupling Vibration Based on SIMPACK and ANSYS, Southwest Jiaotong University, Chengdu, China, 2013.

[20] Y. Q. Deng, "Comprehensive comments on simple-supported box girder on passenger dedicated line," Journal of Railway Engineering Society, vol. 2, no. 1, pp. 65-71, 2005. 